DOI: 10.34220/DSPPD2021_39-46

УДК 37.013+316.3

Петряева Татьяна Андреевна, преподаватель, Воронежский государственный лесотехнический университет имени Г.Ф. Морозова

\author{
РОЛЬ БИОГРАФИЧЕСКОГО МЕТОДА В ПРЕОДОЛЕНИИ \\ НЕГАТИВНЫХ ПОСЛЕДСТВИЙ СОЦИАЛИЗАЦИИ ПОДРОСТКОВ В \\ ПРОСТРАНСТВЕ ЦИФРОВОГО ОБЩЕСТВА
}

\title{
THE ROLE OF THE BIOGRAPHICAL METHOD IN OVERCOMING THE NEGATIVE CONSEQUENCES OF THE SOCIALIZATION OF TEENAGERS IN THE DIGITAL SOCIETY
}

\begin{abstract}
Аннотация: В статье подробно рассматриваются социальные изменения, оказывающие воздействие на формирование личности, влияние искусственного интеллекта и СМИ на жизнь современного человека и подростка в процессе социализации, возможные негативные последствия. Автор исследует проблему нравственной деформации у подростков, вызываемой некоторыми особенностями цифрового общества, анализируя при этом положительный опыт использования биографического метода в европейских странах на примере Германии. В статье также описывается эксперимент, проведенный на базах общеобразовательных учреждений города Санкт-Петербург, подводятся его итоги, доказывающие эффективность использования биографического материала в отечественной системе образования.
\end{abstract}

Abstract: The article examines in detail the social changes that affect the formation of personality, the influence of artificial intelligence and the media on the life of a modern person and a teenager in the process of socialization, and possible negative consequences. The author examines the problem of moral deformation in adolescents caused by certain features of the digital society, while analyzing the positive experience of using the biographical method in European countries on the example of Germany. The article also describes an experiment conducted on the bases of general education institutions of the city of St. Petersburg, summarizes its results, proving the effectiveness of the use of biographical material in the domestic education system.

Ключевые слова: биографии известных людей, биографический материал, социализация, нравственное воспитание, цифровое общество, искусственный интеллект

Keywords: biographies of famous people, biographical material, socialization, moral education, digital society, artificial intelligence

\footnotetext{
${ }^{\circ}$ Петряева Т.А., 2021
} 
Сегодня стало совершенно очевидным, что человечество вступило в принципиально новую эпоху своего существования. В обществе происходят столь стремительные, многогранные и взрывообразные изменения, что говорить о возможности какого-либо достоверного социального моделирования теперь уже весьма трудно. Социологическое прогнозирование столкнулось с той же проблемой, что, например, и научный прогноз погоды. Сделать какойлибо относительно долгосрочный прогноз очень сложно ввиду колоссального массива быстро изменяющихся данных. Все это ставит перед человечеством, его научной и политической элитами новые вызовы и вопросы, которые необходимо не просто обсуждать, а и находить на них адекватные ответы и решения, если, конечно, мы хотим выжить как вид homo sapiens.

Социальная действительность за последние десятилетия претерпела существенные изменения буквально во всех сферах жизни общества. Произошел бум научных открытий, которые повлияли не только на развитие фундаментальных знаний, но и до неузнаваемости преобразили повседневную жизнь, сделав ее, с одной стороны, более комфортной, с другой, динамичной и непредсказуемой. Изменения коснулись медицинской сферы, которая вынуждена бороться с агрессивными и ранее неизвестными болезнями, способными повлиять на жизнедеятельность не только отдельного индивида, но и всего человечества. Значительные перемены произошли в экономической сфере, где явно прослеживается стремление к интеграции мирового экономического пространства, созависимости национальных экономик. Однако такой вектор развития мировой экономики устраивает далеко не каждое государство, поэтому наряду с интеграционными процессами наблюдается отстаивание многими государствами своей экономической независимости. Это оказывает влияние на развитие форм экономической деятельности, появление новых площадок для получения прибыли, манеру ведения бизнеса, уровень требований к профессиональным компетенциям персонала. Значительные изменения коснулись информационной сферы. Огромное количество ITтехнологий кардинально изменили повседневную жизнь, предложив, с одной стороны, удобные и энергосберегающие модели решения насущных проблем, с другой стороны, обозначив немалое количество рисков не только правового, экономического, культурного, но и личностного характера. Каждый из этих 
аспектов влияет на деятельность людей, заставляет их приспосабливаться к новым условиям труда.

Современный человек практически с рождения включен в информационное общество. Сегодня вряд ли кто-то способен представить свою жизнь без тех же интернета и смартфона. А ведь еще двадцать-тридцать лет назад все это казалось немыслимым и фантастическим. По словам профессора кафедры психологии, личности факультета психологии Московского государственного университета Галины Солдатовой, на сегодняшний день смартфон - главный инструмент познания мира, средство коммуникации детей и их развития. Такого многофункционального устройства с колоссальными возможностями у подрастающего поколения никогда раньше не было. При этом он настолько прост в функционировании, что даже совсем маленькие дети зачастую становятся его пользователями. Вот уж действительно - нажми на кнопку и получишь результат. Согласно исследованиям, в течение суток в активном распоряжении детей смартфоны находятся в среднем 4,5 часа. Почти каждого четвертого подростка 14-17 лет можно назвать гиперподключенным (23\% подростков в среднем проводят 9 часов в сутки в интернете) [1, С. 2]. Приведенные данные наглядно демонстрируют и, пожалуй, доказывают, что активными потребителями и создателями развитого искусственного интеллекта будут нынешние дети и подростки. Не стоит рассчитывать, что подобная зависимость от гаджетов пройдет в зрелом возрасте, она, это очевидно, только усилится, - современный мир семимильными шагами двигается к информационному, высокотехнологичному и роботизированному миру. Высказанное предположение подтверждается результатами социологического опроса «Динамика пользования интернетом», проведенного Аналитическим Центром Юрия Левады. Полученные статистические данные указывают на то, что в 2019 г. доля совершеннолетних интернет-пользователей превысила 80процентный уровень. Необходимо обратить внимание, что за последние четыре года наиболее заметный рост ежедневных интернет-пользователей отмечается не только среди молодежи, но и старших возрастных групп. Их численность практически удвоилась с 39 \% до 69 \% на ноябрь 2019 года; среди респондентов в возрасте от 55 лет и старше отмечается троекратное увеличение - с $11 \%$ до $34 \%$ [2, С. 1]. Это совершенно предсказуемая и очевидная ситуация, ведь интернет и его возможности дарят людям не только 
увлекательный досуг, но и оперативное решение повседневных задач (оплата коммунальных услуг, денежные переводы, покупка продуктов и иных вещей, оплата транспорта, управление домашним инвентарем, например, стиральной машиной, кондиционером, роботом-пылесосом т.д.).

В последние десятилетия передовые государства и экономические корпорации стремятся развивать сферу искусственного интеллекта, о чем не раз в своих выступлениях говорили главы государств. Наша страна не отстает от общемировых информационных веяний. Так, например, министр науки и высшего образования РФ Валерий Фальков в одном из интервью обозначил, что в последние годы особую популярность среди молодежи приобретают технические и информационные науки. Сегодня абсолютному большинству понятно, что на первом плане стоят такие направления обучения, как естественные науки (16\%), экономика и менеджмент (16 \%), инженерное дело, технологии и технические науки (15\%) [3, С. 1]. Видится, что значительное влияние на выбор абитуриентов оказывают такие факторы, как цифровизация общества, активное развитие биотехнологий, биоинженерии и кибер-медицины.

Рассуждая над возможностями искусственного интеллекта, лежащего в основе формирования цифрового общества, можно обозначить ряд достоинств и рисков. И если преимущества лежат на поверхности, то риски зачастую одной частью людей не осознаются (по причине недостаточного уровня образования или возрастных особенностей), а другой - просто замалчиваются.

Историк и автор мирового бестселлера «Sapiens: Краткая история человечества» Юваль Ной Харари в своей работе достаточно много размышляет об особенностях работы искусственного интеллекта, его потенциале и дальнейшей судьбе человека в рамках цифрового общества. По мнению Харари, последние достижения в области искусственного интеллекта, в частности, технологии для наблюдения и распознавания лиц могут привести к возникновению оруэлловского общества тотального контроля и сосредоточения власти в руках незначительной группы лиц. Раньше даже в таких тоталитарных государствах, как нацистская Германия или сталинский Советский Союз, режимы не могли все время следить за своими гражданами. Это было весьма желанным, но практически неосуществимым. Однако сейчас мы достигли той степени технического развития, когда новые технологии, сочетающие в себе искусственный интеллект и биотехнологии, биометрические датчики, системы 
навигации, распознавания лиц и голоса, впервые в истории позволяют следить не только за каждым человеком, а и за всеми людьми одновременно. Это может привести к появлению тоталитарных режимов, которые будут намного хуже, чем все, что были в истории до этого времени. И у нас, откровенно говоря, не так уж много времени, чтобы это остановить [4, С. 6] Ключевую роль в сдерживании такого хода событий, конечно же, должны на себя взять страны с развитыми и проверенными на прочность демократиями. Видится, что озвученный социальный риск является не то, чтобы возможным, а и неизбежным. Возникают абсолютно животрепещущие вопросы и вызовы: как сохранить свободу человека, неприкасаемость его личного пространства в ближайшей исторической перспективе (а там, и не за горами, - вообще сохранить себя, как биологический вид), но при этом не отстать в работах по созданию ИИ от государств, ведущих здесь активные исследования и разработки? Как повлиять на ценностные установки людей? Как воспитывать нравственное и, прежде всего, гуманистическое поколение людей? Очевидно, что решение всех этих задач возможно только на глобальном уровне, чтобы буквально каждое государство, каждая элита, политическая, финансовая, научная, была вовлечена в процесс нахождения ответа на возникшие перед нами вызовы. Без консолидации и солидарности эту проблему не решить. Вопрос, ставший перед человечеством, поистине шекспировский: быть или не быть?

Что в этой связи посильно сделать уже сейчас в том же образовательном пространстве? Какие технологии использовать, чтобы минимизировать пагубное воздействие некоторых аспектов современного общества на школьников и студентов, при этом не остановив их позитивного личностного развития? И возможно ли это? Конечно, надо быть реалистами: лишь отчасти. Тот новый контркультурный поток, с которым мы сегодня столкнулись, имеет беспрецедентную идеологическую и финансовую поддержку. И все же...

Думается, что современная школа и в какой-то степени высшие учебные заведения должны взять вектор не столько и не только на достижение предметных результатов, которые в современных реалиях могут оказаться бесполезными в силу высокого темпа развития науки, сколько на формирование моральных основ у обучающихся. Представляется, что для достижения озвученной цели подходит использование биографий известных 
людей, которые помогут тем же подросткам научиться критически анализировать социальную реальность и совершать поступки в поле нравственных, гуманистических ценностей.

Биографии известных людей, как педагогический метод, довольно широко используются в образовательном процессе в европейских странах. Для того чтобы увидеть, как изучение жизни известных общественных деятелей меняет сознание подростков, развивает в них критическое мышление, предлагаем ознакомиться с опытом использования биографического материала на примере такой дисциплины как «Религиоведение», изучаемой в среднем звене в школах современной Германии.

Цель курса заключается в том, чтобы учащиеся могли решать возникающие в их личной жизни ситуации, имея перед собой примеры поступков авторитетных в Германии людей. Открывая тематическую тетрадь, по которой немецкие учащиеся исследуют курс, мы видим оглавление, в котором содержатся имена национальных героев Германии.

Одной из самых значимых фигур в пособии является Пауль Шнайдер. Биографию этой личности учащимся предлагается изучить более углубленно. Ребятам рассказывается о жизненном пути этого немецкого пастора, не принявшего гитлеровской идеологии расизма и нацизма. Ценность этого человека в его личных гуманистических убеждениях, от которых он не отказался даже перед лицом жесточайших пыток и насильственной смерти.

На таких примерах воспитываются подрастающие поколения послевоенной Германии. Они не позволяют себе забывать своих настоящих, истинных героев, включая их в свою собственную жизнь. Они не закрывают глаза на горькую правду, ошибки и даже преступления своего государства. Ведь только через осознание подлинной истории своей страны стало возможным возрождение совершенно иной Германии, где ценности свободы, демократии и достоинства человеческой личности являются национальными, государственными и общественными приоритетами. Именно поэтому современное немецкое образование стремится не только дать багаж теоретических знаний, но и научить своих воспитанников помнить о прошлом, думать о происходящем через призму нравственных ориентиров. Эту задачу немецкие школы реализуют непосредственно через использование биографий известных людей. Во многих школах Берлина существует отдельный предмет, где учащиеся изучают исторические события на основе героических поступков 
своих соотечественников. Особенность изучения данного предмета состоит в том, что учитель позволяет ребятам самостоятельно оценивать поступок человека, рассуждать и приходить к своему мнению, которое подчас бывает неординарным, однако от этого не лишённого нравственного ядра.

Совершенно очевидно, что использование биографического материала в подобном ключе может оказывать существенную роль на воспитание и образование и российских школьников и студентов. Видится, что наиболее эффективным использование биографического метода возможно в процессе изучения уже имеющихся предметов в классах среднего и старшего звена, на первых курсах вузов.

С целью проверки эффективности биографического метода автором был проведен своеобразный научный эксперимент на базе общеобразовательных учреждений. В течение 2017-2018 учебного года среди учащихся параллелей 69 классов ГБОУ гимназии № 114 и ГБОУ СОШ № 605 Выборгского района Санкт-Петербурга были созданы лабораторные и экспериментальные классы. Всем учащимся предлагалась небольшая анонимная работа, в которой были задания на выявление ценностных установок учащихся. Вопросы заданий рассматривали отношения подростков к семейным ценностям, моральной ответственности, любви к Родине, многообразию жизненных позиций и умению находить компромисс в диалоге. По результатам диагностических работ во всех классах проводились уроки на одни и те же темы. В экспериментальных классах (в отличие от контрольных) присутствовал биографический материал, на основе которого изучалась или закреплялась тема урока [5, С. 88-90]. Для сравнения результатов после закрепления материала проводились самостоятельные и творческие работы, которые были нацелены на проверку изменения нравственных ориентиров у учащихся, их гражданских и личностных установок [6, С. 72-73].

Результаты проведенной работы показали, что ценностные установки учащихся экспериментальных классов претерпели значительные изменения в лучшую сторону, поскольку ответы учащихся стали более вдумчивыми и носили оттенок осуждения аморального поведения [6, С. 73].

Подводя итог, хочется сказать, что биографический метод в достаточной степени уникален. Его познавательная и воспитательная роль в социализации школьников и студентов совершенно очевидна [5, С. 326]. Использование в образовательной среде биографий известных людей способствует формированию и закреплению в их сознании гуманистических ценностей. 
Видится, что приоритет именно таких нравственных ориентиров в умах тех, кто завтра станет разработчиком новых технологий, кто будет управлять компаниями и государствами, дает надежду на сохранение свободы человеческой личности, да и вообще нас, как биологического вида, в цифровом обществе.

\section{БИБЛИОГРАФИЧЕСКИЙ СПИСОК}

1. Горячева Ю. Психолог Галина Солдатова: Именно дети и подростки идут в фарватере процесса цифровой трансформации общества // Информационный портал фонда «Русский мир». URL: https://russkiymir.ru/publications/270257 (дата обращения: 18.04.2021).

2. Аналитический Центр Юрия Левады. URL: levada.ru/2019/12/05/dinamika-polzovaniya-internetom/print/ (дата обращения: 18.04.2021).

3. Асатурян Д. М., Спрос на высшее образование со стороны выпускников 11-х классов в 2020 году // Мониторинг экономики образования. 2020. - № 36. - С. 1-7.

4. Синергия: [сайт]. URL: http://Synergy Online Forum: [сайт]. URL: synergyglobal.ru/forums/businessmobilization/2020 (дата обращения: 18.04.2021).

5. Петряева Т. А. Влияние биографий известных людей на формирование нравственных установок у современных школьников // Актуальные вопросы современной наук и образования: сборник статей IV Международной научнопрактической конференции (15 февраля 2021 г.). - Петрозаводск: МЦНП «Новая наука», 2021. - 259 с.

6. Петряева Т. А. Использование биографий известных людей как средство воспитания гражданственности и патриотизма в современном образовательном процессе // Современное образование: опыт прошлого, взгляд в будущее: сборник статей Всероссийской методико-практической конференции (6 декабря 2020 г.). - Петрозаводск: МЦНП «Новая наука», 2020. $-268 \mathrm{c}$. 